\section{Digestive \\ Surgergery}

Anders, S. 507

Bärlehner, E. 507

Bermoser, K. 500

Bittner, R. 511

Büchler, M.W. 452, 484, 502

Candinas, D. 494

Eypasch, E. 518

Farke, S. 489

Frauenschuh, D. 489

Friess, H. 484

Giger, U. 473

Gloor, B. 494

Hackert, T. 502

Hartel, M. 484
Hennig, R. 484

Hünerbein, M. 479

Jacobi, C.A. 459

Kienle, P. 453

Koch, M. 453

Kraas, E. 489

Krähenbühl, L. 473

Lefering, R. 518

Leibl, B.J. 511

Lippert, H. 464

Ly, Q. 494

Müller, J.M. 459

Neugebauer, E.A.M. 518

Opitz, I. 459
Rau, B. 479

Reymond, M.A. 464

Sauerland, S. 518

Schäfer, M. 473

Schlag, P.M. 479

Schmedt, C.-G. 511

Schwetling, R. 507

Steiner, E. 500

Steiner, P. 500

Steinert, R. 464

Tempia-Caliera, A.A. 484

Uhl, W. 502

Wenger, F. 459

Z'graggen, K. 452

\title{
Subject Index Vol. 19, No. 6, 2002
}

Appendectomy 518

Cancer 464

Cholecystectomy 489

Clinical trials 459

Colon surgery 502

Complications 464

Conventional surgery 518

Disseminated tumor cells 453

Experimental studies 459

Gallbladder cancer 489

Gastrointestinal cancer 453

- malignancy 473,479

Hepatic cysts 494

Immunology 459
Inguinal hernia 511

Laparoscopic approach 494

- hernia repair 500

- surgery 489,518

- ultrasound 479

Laparoscopy 464, 473, 484, 507

Micrometastases 453

Minimal invasive surgery 459

- residual disease 453

Oncology 459

Pancreas 507

Pancreatic cancer 484

Peritoneum 453

Port-site recurrences 464
Preoperative tumor staging 473

Randomized trials 511

Resection 507

Results 511

Review 511

Specimen retrieval 502

Staging 479, 484

Surgery 494

Surgical technique 511

Transabdominal preperitoneal mesh prosthesis 500

Ultrasound 473

\section{KARGER}

(c) 2002 S. Karger AG, Basel

Fax + 41613061234

E-Mail karger@karger.ch

www. karger.com
Accessible online at www. karger.com/dsu 